\title{
Physical and mental growth and development in children with congenital hypothyroidism: a case-control study
}

Javad Nazari ${ }^{1}$, Kimia Jafari ${ }^{2}$, Maryam Chegini ${ }^{2}$, Akram Maleki ${ }^{2}$, Pari MirShafiei ${ }^{2}$, Ali Alimohammadi ${ }^{3}$, Yasan Kazemzadeh ${ }^{4}$, Reihaneh Mikaeliyan ${ }^{2}$ and Saeed Amini ${ }^{4,5^{*}}$ (D)

\begin{abstract}
Introduction: The clinical complications of congenital hypothyroidism such as brain disorders are very subtle and are not recognizable in infancy period. They are recognizable when it is too late for treatment or prevention. General screening of newborns is effective in diagnosing congenital hypothyroidism and initiating initial treatment. The aim of this study is to compare the physical and mental growth pattern of children with congenital hypothyroidism with healthy ones.
\end{abstract}

Methods: This case-control study was performed on 34 patients and 68 healthy children who were matched in terms of inclusion and exclusion criteria. Children development screening test (ASQ), children development assessment test (Bayley), preschool Wechsler intelligence scale (WPPSI) and age and steps questionnaire of emotional social development (ASQ-SE) were completed by trained questioners. Data were analyzed using STATA software.

Results: The results indicated that there was no significant difference between the mean of verbal $(P=0.77)$, nonverbal $(P=0.81)$ and general $(P=0.66) \mathrm{IQ}$ in permanent and transient patients and healthy individuals. Also, there was no significant difference between the mean of different ranges of ASQ test (including communication, delicate and large movements, problem solving and social) at 12 months and 42 months $(P<0.05)$. According to Bayley test, there was no significant difference between the cases (permanent and transient) and controls in the cognitive $(P=0.42)$ and expressive $(P=0.38)$ categories. The difference was significant in the perceptual $(P=0.011)$, large $(P=0.03)$ and delicate $(P=0.04)$ movements categories.

Conclusion: This study emphasized on the high effectiveness of neonate hypothyroidism screening program, so that the difference between 3.5 years old children with and without this disease has decreased significantly. Early diagnosis of the patients, while creating beneficial effects for patients and increasing quality of life, cause reduction in the long-term costs of the health system.

Keywords: Physical development, Mental development, Congenital hypothyroidism, Emotional intelligence, Development criteria

\footnotetext{
*Correspondence: s.amini@arakmu.ac.ir

${ }^{5}$ Department of Health Services Management, Health School, Arak University of Medical Sciences, Arak, Iran

Full list of author information is available at the end of the article The original online version of this article was revised to correct the authors' affiliations.
}

\section{Introduction}

Congenital hypothyroidism $(\mathrm{CH})$ is a disease that occurs due to defective production of thyroid hormones from the birth. If the defect occurs in the thyroid glands itself, it is called "primary hypothyroidism" and if there is a defect in the release of TSH, it is called "central 
hypothyroidism". Congenital types of hypothyroidism are not inherited and usually occurs due to thyroid dysgenesis. In some cases, hypothyroidism is familial resulting from inborn errors in synthesis of thyroid hormone that usually is due to problems with the synthesis of thyroid hormone with the goiter presentation. Most infants with congenial hypothyroidism are identified in the neonatal screening in the first weeks after birth (first month) before the onset of clinical signs and symptoms of disease [1].

$\mathrm{CH}$ is one of the most common predictable causes of mental retardation in children, that early diagnosis and treatment can prevent catastrophic consequences. The clinical complications of congenital hypothyroidism such as brain disorder and injury and nerve growth retardation are very subtle and are not recognizable in infancy and can be recognized when it is too late for treatment or prevention. So, general screening of newborns is effective in diagnosing congenital hypothyroidism and initiating on time initial treatments [2].

Most infants with hypothyroidism are normal at birth and show no signs of the disease. However, follow-up studies in these patients indicate that delays in the diagnosis and treatment, in addition to known neurological complications such as mental retardation, developmental disorders (poor motor coordination, imbalance), eye aberrations, and learning difficulties, may lead to stunted growth pattern and short stature [3, 4].

The incidence rate of $\mathrm{CH}$ varies from 1:2000 to 1:4000 in different countries. As an example, this rate is reported to be around 1 patient in 3500 to 5000 in the United States, 1 in 3000 in Europe and 1 in 5700 in Japan [5, 6]. Based on the screening results, the average incidence of the disease in Iran was 2.9 cases per thousand people (1 in 334 live births), 3.8 in the population covered by Arak University of Medical Sciences (1 in 258 live births) [7].

Previous studies have focused mainly on the primary items of children growth such as height and weight and have not addressed developmental issues. In a study by Faizi et al. in 2013, the growth status of children with hypothyroidism that were diagnosed in the congenital hypothyroidism screening program in Isfahan was compared with healthy children in the same age group. In their study, they measured and reported height, weight, and head circumference for case and control groups. The results showed that the range of these indicators in the affected children was significantly different from healthy ones at the beginning of diagnosis, but the disorder in head size decreased to less than $3 \%$ of normal head circumference at the age of 3 and height gradually decreased to $3 \%$ and $9 \%$ of normal height in girls and boys, respectively. However, weight index difference was still more than $3 \%$ of normal weight in both sexes. Therefore, it can be concluded that patients with congenital hypothyroidism had growth disorders that was improved during follow-ups [4]. One of the shortcomings of the Faizi et al. study is that they have not studied psychological and developmental indicators of children. In the other study, Khabiri et al. compared the developmental indices of children with congenital hypothyroidism with healthy children using the age and steps questionnaire of ASQ in 2017. According to their results, the mean score of developmental indicators in children with congenital hypothyroidism was significantly lower than the healthy group [8]. In this study, only the ASQ questionnaire was used and other tools and questionnaires to measure physical and mental status were ignored.

There are studies in other countries that have compared developmental status of $\mathrm{CH}$ children with healthy ones. Accordingly, SUN et al. in 2012 in Najing, China studied the treatment outcomes of children with congenital hypothyroidism for a 12-year period. They included 163 infected and 163 healthy children in their study. According to the results, height, weight and body mass of children from 6 months to 6 years of age were not significantly different from the control group, although the affected children were at higher risk for overweight and obesity. Affected Children had lower developmental quotient (DQ) than the control group in all aspects of GESell test. Therefore, the researchers have recommended that affected children diagnosed and treated by birth screening have normal growth and neuromotor development [9]. In another study by Van Der Sluijs Veer et al., the quality of life, social development and self-esteem of 69 young people born with congenital hypothyroidism at birth screening in the Netherlands between 1981 and 1982 were assessed using three related questionnaires. The results showed that they have lower quality of life, self- esteem and social development than normal population [10].

The strength point of the present study compared to other studies is that the physical and mental dimensions of children using questionnaires and various tools including ASQ, WPPSI, ASQ- SE, BAELEY tests, as well as children's health files are assessed in the present study. In other words, using these tools, children's verbal, non-verbal and general Intelligence Quotient (IQ), communication scale development, large movements and delicate movements, evolution on a cognitive, linguistic and motor scale, children emotional and social development, indices of head to age ratio, stunting and wasting have been compared between healthy and affected children. Also, the previous studies have not studied separate assessments for transient and permanent hypothyroidism children and have not compared them with healthy ones. 
They only have investigated the general issue of congenital hypothyroidism [11-13].

Regarding the necessity of conducting this study, firstly, no study has been conducted with the characteristics of the present study previously. The second is that more than 15 years have passed since the implementation of the national program of neonatal hypothyroidism screening in Iran. This necessitate the evaluation of its effectiveness. Therefore, the present study is designed to compare physical and mental development of children with transient and permanent $\mathrm{CH}$ with healthy children. This makes possible to accurately describe the current status and therefore provide practical information to health policy makers to redesign this national program.

\section{Method}

\section{Study population}

This is a case-control study that was performed on all three and a half years old children with transient or permanent $\mathrm{CH}$. These children are diagnosed in the national screening program and treatment measures have been performed for them. The number of these children was 34 at the beginning of 2020 in Markazi province. Inclusion criteria included all children aged three and a half years who have been diagnosed and treated as patients in the $\mathrm{CH}$ screening program. Exclusion criteria included concurrent infections and diseases such as preeclampsia, intrauterine growth retardation, and genetic problems such as Down syndrome or severe anomalies. The comparison group included healthy three and a half years old children.

\section{Levothyroxine replacement therapy}

On the basis of Neonatal Hypothyroidism Screening Program of Iran, the limit of distinction for primary hypothyroid screening test in neonates is TSH equal to $5 \mathrm{mu} / \mathrm{l}$ in the samples taken in the first week of birth and TSH equal to $4 \mathrm{mu} / \mathrm{l}$ for the samples taken from day 8 and onwards. Accordingly, for the samples taken in the first week of birth, TSH result lower than $5 \mathrm{mu} / \mathrm{l}$ is considered as normal, between 5-9.9 recall for re-screening, and between 10-19.9 recall for confirmation tests including $\mathrm{TSH}, \mathrm{T} 3 \mathrm{Ru}, \mathrm{T} 4$ and/or Free T4, equal or higher than 20 recall for taking intravenous sampling and starting treatment. It is expected that $\mathrm{T} 4$ concentration increase to $10 \mu \mathrm{g} / \mathrm{dl}$ during 2 weeks and TSH concentration become normal until 1 month after starting treatment by suitable dose of levothyroxine. The proposed dose for levothyroxine is $10-15 \mu \mathrm{g} / \mathrm{kg} /$ day. However, it is better to start treatment with the dose of $50 \mu \mathrm{g} /$ day for neonates with very low T4 (equal or lower than $5 \mu \mathrm{g} / \mathrm{dl}$ ). Drug interactions and change in levothyroxine dose should be considered [14].

\section{Sampling method}

The case group included all three and a half years old children with transient and permanent $\mathrm{CH}$ who were diagnosed through at birth screening tests. This group was included in the study by census. So that, the study sample was equal to the research population (that is 34 patients). Random sampling method was used among healthy three and a half years old children to select the control group. This increases comparability with the case group. For this purpose, twice the number of cases, i.e. 68 people, were selected as the control group by matching the economic and social factors (age, sex, economic and social status of the household, place of residence, etc.). The healthy group were selected using the information contained in the health files of healthcare centers. Based on the indices of age, sex, parents' education, household economic status, the most identical person with the patient in each center was selected and included in the study.

\section{Administration}

Questionnaires were trained on how to measure growth and development of affected and healthy children using the related questionnaires and tools. These questionnaires included second edition of Age and Steps Questionnaire of Social and Emotional development (ASQ-SE-2) developed by Squires et al. (2015) [15]; third edition of child development screening test (ASQ-3) developed by Squires \& Bricker (2009) [16]; third edition of developmental assessment test for children (Bayley) developed by Bayley [17]; and third edition of preschool Wechsler intelligence scale (WPPSI-III) developed by Wechsler (2002) [18].

The ASQ screening questionnaires were completed by asking questions from the patient's family, and this way, a score was given to each child for his/her developmental status. The BAELEY developmental test for the children were completed in the specialized center for children growth and development. Finally, the preschool Wechsler intelligence scale (WPPSI) was used. This tool is an individual practice clinical tool that is used to measure the intelligence of children aged 2 years and 6 months to 7 years and three months. This tool is a revised version of the preschool Wechsler IQ scale wppis-r-1989. The Wechsler test includes sub-test scores and total scores that this scores indicate mental performance in the psychological, practical, and verbal ranges. This test has 14 sub-tests including cubes design, information, matrix argument, vocabulary, visual concepts, symbol search, word reasoning, decoding, comprehension, completing images, similarities, word comprehension, joining parts, naming images. The validity and reliability of this test are calculated by Abedi et al. (2015). Based on test-retest 
reliability, reliability of subsets from 0.44 to 0.94 ; and using the reliability of the two-half test for subtests, it was in the range of 0.70 to 0.98 . The validity of the scale was assessed using the correlation of subtests with each other, and the concurrent validity of the Wechsler revised scale. The correlation coefficients of verbal, practical and total IQs are $0.84,0.74$ and 0.85 , respectively, which are very close to the coefficients reported in the main scale guide $(0.80,0.8$, and 0.82$)$ [19].

The age and steps questionnaire of emotional social development (ASQ- SE) is an international and standardized questionnaire with high validity and reliability, and its translation has been done by Iran ministry of health to be used in healthcare centers of the country [20]. In this questionnaire, the status of social and emotional intelligence of children is compared with the control group.

Height, weight and head circumference variables are among the periodic care that are measured for all Iranian children and are recorded in children's health files. In this study, trained questioners extracted these indicators from the documents and based on them, BMI, Wasting and stunting indices were calculated.

\section{Method of analysis}

Kolmogorov-Smirnov test was used to assess the normality. This test indicated that P-value is not significant in each one of the studied indicators including verbal, non-verbal and total intelligence, ASQSE, communication ranges, large and delicate movements, problem solving, social, cognitive, perceptual, expressive, dynamic, weight, height, head circumference and BMI. This indicated that all of the indices are normal, so one-way ANOVA test was used to evaluate the mean differences. The difference between two groups was considered significant when the P-value was less than 0.05. Data were analyzed using STATA software version 14 .

\section{Results}

About half of the patients lived in Arak city, and the rest lived in the other cities of the province. $91 \%$ of patients lived in urban ranges and the rest in villages. More than half of the patients $(55.88 \%)$ had transient hypothyroidism and the rest had permanent hypothyroidism. $65 \%$ of the patients were female and $70 \%$ of patients received their treatment before 28 days of age (Table 1 ).

Mean birth weight (SD) for controls 1 , controls 2 and cases was $2770 \pm 960,2850 \pm 870$ and $3150 \pm 1180$, respectively. $78 \%, 72 \%$ and $49 \%$ of the controls 1 , controls 2 and cases had normal delivery, respectively. $7.34 \%$ and $4.4 \%$ of the cases had history of family thyroid disorders and congenital anomaly, respectively. The control group had no history of family thyroid disorders. TSH level for control groups was between 3.1-5.8 and for the cases was higher than 10 . There was no significant correlation between the TSH level and gender $(P=0.61)$. Moreover, there was no significant difference between gender and the prevalence of hypothyroidism $(P=0.91)$. We considered TSH $>10$ and free $\mathrm{T} 4<1.6$ as hypothyroidism.

The results showed that there was no significant difference between the mean of verbal intelligence $(P=0.77)$, non-verbal intelligence $(P=0.81)$ and total intelligence $(P=0.66)$ in the patients (permanent and transient) and healthy individuals (control 1 and 2) (Table 2). Also, no significant difference was observed between the mean of communication category of ASQ at 12 months $(P=0.78)$ and 42 months $(P=0.53)$ in permanent and transient patients and healthy individuals. The results showed that there was no significant

Table 1 Demographic characteristics of the hypothyroidism patients (cases) and healthy individuals (controls 1\&2)

\begin{tabular}{|c|c|c|c|c|c|c|}
\hline \multirow[t]{2}{*}{ Variables } & \multicolumn{2}{|l|}{ Control 1} & \multicolumn{2}{|l|}{ Control 2} & \multicolumn{2}{|l|}{ Cases } \\
\hline & Number & Percent & Number & Percent & Number & Percent \\
\hline \multicolumn{7}{|l|}{$N$} \\
\hline & 34 & 33.3 & 34 & 33.3 & 34 & 33.3 \\
\hline \multicolumn{7}{|l|}{ Gender } \\
\hline Male & 27 & 79.41 & 9 & 26.47 & 22 & 64.71 \\
\hline Female & 7 & 20.59 & 25 & 73.53 & 12 & 35.29 \\
\hline \multicolumn{7}{|c|}{ Body mass index ( $\mathrm{kg} / \mathrm{m} 2)$} \\
\hline Fat & 0 & 0 & 1 & 3.03 & 1 & 3.23 \\
\hline Over weight & 2 & 6.25 & 2 & 9.09 & 2 & 6.45 \\
\hline Normal & 30 & 93.75 & 30 & 90.91 & 28 & 90.32 \\
\hline \multicolumn{7}{|c|}{ Place of resident } \\
\hline Urban & 31 & 91.18 & 31 & 91.18 & 31 & 91.18 \\
\hline Rural & 3 & 8.82 & 3 & 8.82 & 3 & 8.82 \\
\hline
\end{tabular}


Table 2 Intelligence Coefficient (IQ) scores between controls 1 and controls 2 and cases

\begin{tabular}{llllll}
\hline Group & SS & DF & MS & F & Prob \\
\hline Verbal (IQ) & & & & & \\
Between groups & 39.93 & 2 & 17.97 & 0.06 & 0.9397 \\
Within groups & $27,155.05$ & 97 & 279.94 & & \\
Total & 2719.99 & 99 & 274.65 & & \\
Nonverbal (IQ) & & & & & \\
Between groups & 626.94 & 2 & 313.47 & 1.03 & 0.36 \\
Within groups & $29,598.05$ & 97 & 305.13 & & \\
Total & 30,225 & 99 & 305.3 & & \\
Total & & & & & \\
Between groups & 142.55 & 2 & 71.27 & 0.31 & 0.7375 \\
Within groups & $22,633.8$ & 97 & 233.33 & & \\
Total & $22,776.36$ & 99 & 230.06 & & \\
\hline
\end{tabular}

SS: Sum of Squares; DF: Degree Free; MS: Mean Squares; F: F-Ratio; Prob: Probability

difference between the mean of large movements category of ASQ at 12 months $(P=0.69)$ and 42 months $(P=0.86)$ in permanent and transient patients and healthy individuals. According to the results, there is no significant difference between the mean of delicate movements category of ASQ at 12 months $(P=0.15)$ and 42 months $(P=0.27)$ in permanent and transient patients and healthy individuals. The results indicated that there is no significant difference between the mean of problem solving category of ASQ at 12 months $(P=0.50)$ and 42 months $(P=0.16)$ in permanent and transient patients and healthy individuals. According to the results, there is no significant difference between the mean of social range category of ASQ at 12 months $(P=0.41)$ and 42 months at $(P=0.29)$ in permanent and transient patients and healthy individuals (Tables 3 , 4).

According to the results, there was no significant difference between the mean of cognitive category of Bayley test in permanent and transient patients and healthy individuals $(P=0.38)$.

According to the results, there was a significant difference between the mean of perceptual category of Bayley test in permanent and transient patients and healthy individuals $(P=0.011)$. Bonferroni and Scheffe tests were used to determine the location of difference in this category. Both two tests indicated difference between cases, control 1 and control 2 groups, as well as between permanent patients and healthy individuals.

According to the results, there was no significant difference between the mean of expression category $(P=0.26)$ in Bayley test in permanent and transient patients and healthy individuals.
According to the results, there was a significant difference between the mean of delicate $(P=0.04)$ and large movements $(P=0.03)$ categories of Bayley test in permanent and transient and healthy patients. Bonferroni and Scheffe tests were used to determine the difference place in this categories. Both tests showed difference between permanent patients and healthy individuals.

The 3rd, 15th, 50th, 85th, and 97th percentiles for height, weight, and head circumference of both sexes were determined and compared with the control group and WHO values (Table 5). The percentiles of weight, height, and head circumference of studied patients were not significantly different from control group and WHO values $(P>0.01)$. Accordingly, there was no significant difference between the mean of weight to age ratio in permanent and transient patients and healthy individuals $(P=0.50)$, between the mean of height to age ratio in permanent and transient patients and healthy individuals $(P=0.35)$, between the mean of weight to height ratio in permanent and transient patients and healthy individuals $(P=0.40)$, and between the mean of BMI in permanent and transient patients and healthy individuals $(P=0.12)$. However, there was a significant difference between the mean of head circumference to age in permanent and transient patients and healthy individuals $(P=0.04)$. Bonferroni and Scheffe tests to determine the location of the difference in this category indicated that both tests show no difference between permanent patients and healthy people.

\section{Discussion}

In the absence of congenital hypothyroidism treatment, patients will have linguistic, functional and full-scale intelligence lower than healthy individuals. One of the outstanding results of this study is emphasis on effectiveness of pediatric hypothyroidism screening program. So that, comparing 3.5 years old affected and healthy children indicated that there is no significant difference between verbal, nonverbal and general IQ as well as categories of communication, large and delicate movements, problem solving and social ASQ at 12 and 42 months, and also categories of cognitive, expressive and delicate of Bayley test in transient and permanent hypothyroidism and healthy children. These indicates that therapeutic measures for children with transient and permanent hypothyroidism have been done well and the integration of neonatal hypothyroidism screening program in Iran health system in 2005 has been successful. In other words, like the vaccination program for children, which has been carried out in all cities and villages of the country for decades ago, this program is also carried out throughout the country. This program has paved the way 
Table 3 ASQ categories between controls 1 and controls 2 and cases

\begin{tabular}{|c|c|c|c|c|c|c|}
\hline Group & SS & df & MS & $F$ & Prob & \\
\hline \multicolumn{7}{|c|}{ Communication } \\
\hline \multirow[t]{3}{*}{12 Monthly } & Between groups & 3.92 & 2 & 1.96 & 0.05 & 0.9511 \\
\hline & Within groups & 3364.05 & 86 & 39.1 & & \\
\hline & Total & 3367.97 & 88 & 38.27 & & \\
\hline \multirow[t]{3}{*}{42 Monthly } & Between groups & 10.78 & 2 & 5.39 & 0.5 & 0.6112 \\
\hline & Within groups & 925.29 & 85 & 10.88 & & \\
\hline & Total & 936.07 & 87 & 10.75 & & \\
\hline \multicolumn{7}{|c|}{ Large movements } \\
\hline \multirow[t]{3}{*}{12 Monthly } & Between groups & 3926.44 & 2 & 1936.22 & 1.1 & 0.3383 \\
\hline & Within groups & $153,805.57$ & 86 & 1788.43 & & \\
\hline & Total & $157,732.02$ & 88 & 1792.4 & & \\
\hline \multirow[t]{3}{*}{42 Monthly } & Between groups & 5.72 & 2 & 2.86 & 0.11 & 0.8986 \\
\hline & Within groups & 2230.35 & 85 & 26.24 & & \\
\hline & Total & 2236.07 & 87 & 25.7 & & \\
\hline \multicolumn{7}{|c|}{ Delicate movements } \\
\hline \multirow[t]{3}{*}{12 Monthly } & Between groups & 60.75 & 2 & 30.37 & 1.29 & 0.2797 \\
\hline & Within groups & 2020.14 & 86 & 23.49 & & \\
\hline & Total & 2080.89 & 88 & 23.64 & & \\
\hline \multirow[t]{3}{*}{42 Monthly } & Between groups & 138.9 & 2 & 69.45 & 0.73 & 0.4863 \\
\hline & Within groups & 8119.04 & 85 & 95.51 & & \\
\hline & Total & 8257.95 & 87 & 49.91 & & \\
\hline \multicolumn{7}{|c|}{ Problem solving } \\
\hline \multirow[t]{3}{*}{12 Monthly } & Between groups & 12.85 & 2 & 6.42 & 0.27 & 0.7673 \\
\hline & Within groups & 2081.52 & 86 & 24.2 & & \\
\hline & Total & 2094.38 & 88 & 23.79 & & \\
\hline \multirow[t]{3}{*}{42 Monthly } & Between groups & 123.01 & 2 & 61.5 & 1.95 & 0.1490 \\
\hline & Within groups & 2684.94 & 85 & 31.58 & & \\
\hline & Total & 2807.95 & 87 & 32.27 & & \\
\hline \multicolumn{7}{|l|}{ Social } \\
\hline \multirow[t]{3}{*}{12 Monthly } & Between groups & 123.81 & 2 & 61.9 & 1.46 & 0.2377 \\
\hline & Within groups & 3644.16 & 86 & 42.37 & & \\
\hline & Total & 3767.97 & 88 & 42.81 & & \\
\hline \multirow[t]{3}{*}{42 Monthly } & Between groups & 77.67 & 2 & 38.83 & 0.96 & 0.3852 \\
\hline & Within groups & 3421.19 & 85 & 40.24 & & \\
\hline & Total & 3498.86 & 87 & 40.21 & & \\
\hline
\end{tabular}

SS: Sum of Squares; DF: Degree Free; MS: Mean Squares; F: F-Ratio; Prob: Probability

for the implementation of other congenital metabolic diseases such as phenylketonuria and fauvism [21,22].

This study showed that early therapies, in addition to improving IQ and cognitive skills, and individual-social development are effective also in improving motor functions, motor perceptual skills and visual perception, and executive functions such as memory, planning, speech and language. Early detection of affected people, while creating beneficial effects for patients and increasing their quality of life, reduces the long-term costs of the healthcare system.
In spite of highly effective on time cognitive and curative treatments performed for $\mathrm{CH}$ patients, but the study indicated that there is a significant difference between the affected and healthy children regarding the categories of perceptual, large and delicate movements of Bayley and also head circumference. According to the Rahmani et al. study, despite timely treatment of $\mathrm{CH}$ cases, but children with permanent hypothyroidism have a higher IQ deficit than transient ones. So that Children with $\mathrm{PCH}$ had 4 times less intelligent than children with $\mathrm{TCH}$ [23]. These cases indicate the necessity of performing reforms on 
Table 4 Bayley categories between controls 1 and 2 and cases

\begin{tabular}{|c|c|c|c|c|c|}
\hline Group & SS & df & MS & $F$ & Prob \\
\hline \multicolumn{6}{|l|}{ Cognitive } \\
\hline Between groups & 19.65 & 2 & 9.82 & 0.99 & 0.3763 \\
\hline Within groups & 955.51 & 96 & 9.95 & & \\
\hline Total & 975.17 & 98 & 9.95 & & \\
\hline \multicolumn{6}{|l|}{ Perceptual } \\
\hline Between groups & 104.8 & 2 & 52.4 & 4.72 & 0.011 \\
\hline Within groups & 1066.48 & 96 & 11.1 & & \\
\hline Total & 1171.29 & 98 & 11.95 & & \\
\hline \multicolumn{6}{|l|}{ Expression } \\
\hline Between groups & 11.89 & 2 & 5.94 & 1.34 & 0.2658 \\
\hline Within groups & 425.09 & 96 & 4.42 & & \\
\hline Total & 436.98 & 98 & 4.45 & & \\
\hline \multicolumn{6}{|c|}{ Delicate movements } \\
\hline Between groups & 56.98 & 2 & 28.49 & 1.75 & 0.04 \\
\hline Within groups & 1566.42 & 96 & 16.31 & & \\
\hline Total & 1623.41 & 98 & 16.56 & & \\
\hline \multicolumn{6}{|l|}{ Large movements } \\
\hline Between groups & 9.71 & 2 & 4.58 & 1.39 & 0.03 \\
\hline Within groups & 335.63 & 96 & 3.49 & & \\
\hline Total & 345.35 & 98 & 3.52 & & \\
\hline
\end{tabular}

SS: Sum of Squares; DF: Degree Free; MS: Mean Squares; F: F-Ratio; Prob: Probability national program of $\mathrm{CH}$ screening on the backgrounds of on time treatment and also supervision on its processes.

Previous case-control studies that have compared people with congenital hypothyroidism and healthy children only have focused on the $\mathrm{CH}$ risk factors. In the other words, these studies have examined what underlying factors are present in affected children that are not present in healthy ones and thus attributed the cause of the disease to those factors. While in the present study, this issue was investigated that to what extent $\mathrm{CH}$ children after several years of diagnosis and treatment are as healthy as normal children in terms of various physical and intelligence variables $[24,25]$.

The important point about congenital hypothyroidism screening is to use a same and standard method all over the country and world in order to achieve good results. At the moment, different methods such as TSH measurement at baseline following T4 measurement backup, T4 measurement at baseline following TSH measurement and simultaneous TSH and T4 measurement are used for $\mathrm{CH}$ screening. This indicates that there is no same protocol globally for this work [26]. Inside Iran, also, depending on the child place of birth and parents' knowledge, attitude and practice, the screening process may be performed incompletely, non-standard or in inappropriate

Table 5 Percentile of head circumference $(\mathrm{cm})$, weight $(\mathrm{gr})$ and height $(\mathrm{cm})$ for age for permanent and transient patients, and healthy and $\mathrm{WHO}$ values

\begin{tabular}{|c|c|c|c|c|c|c|c|c|c|c|}
\hline & \multicolumn{2}{|l|}{$3 r d$} & \multicolumn{2}{|l|}{ 15th } & \multicolumn{2}{|l|}{ 50th } & \multicolumn{2}{|l|}{ 85th } & \multicolumn{2}{|l|}{ 97th } \\
\hline & $F$ & $M$ & $F$ & $M$ & $F$ & $M$ & $F$ & $M$ & $F$ & $M$ \\
\hline \multicolumn{11}{|l|}{ Head } \\
\hline Permanent $p$ & 46.3 & 47.3 & 47.3 & 48.0 & 48.8 & 49.5 & 50.3 & 51.3 & 51.3 & 52.6 \\
\hline Transient P & 46.3 & 47.1 & 47.6 & 48.5 & 49.4 & 49.5 & 50.5 & 51.4 & 51.5 & 52.6 \\
\hline Healthy ones & 46.4 & 47.6 & 47.7 & 48.6 & 49.4 & 49.9 & 50.7 & 51.3 & 51.4 & 52.7 \\
\hline WHO values & 46.3 & 47.2 & 47.5 & 48.4 & 49.0 & 49.9 & 50.4 & 51.4 & 51.6 & 52.6 \\
\hline \multicolumn{11}{|l|}{ Weight } \\
\hline Permanent $p$ & 11.4 & 11.6 & 12.9 & 13.8 & 15.2 & 14.1 & 16.2 & 17.1 & 18.8 & 19.0 \\
\hline Transient $P$ & 11.8 & 12.1 & 13.4 & 14.2 & 14.9 & 15.7 & 17.6 & 17.7 & 18.5 & 19.6 \\
\hline Healthy ones & 11.6 & 11.6 & 13.5 & 14.7 & 15.3 & 16.5 & 17.1 & 17.5 & 19.1 & 19.6 \\
\hline WHO values & 11.8 & 12.2 & 13.1 & 13.5 & 15.0 & 15.3 & 17.3 & 17.5 & 19.5 & 19.4 \\
\hline \multicolumn{11}{|l|}{ Height } \\
\hline Permanent $p$ & 89.4 & 91.6 & 94.1 & 94.9 & 98.7 & 99.3 & 103.0 & 104.2 & 105.6 & 104.7 \\
\hline Transient P & 88.7 & 92.6 & 95.4 & 92.7 & 97.5 & 96.8 & 103.5 & 105.8 & 104.1 & 105.6 \\
\hline Healthy ones & 91.3 & 92.4 & 95.0 & 95.3 & 99.4 & 99.8 & 103.7 & 104.5 & 106.9 & 107.5 \\
\hline WHO values & 91.4 & 92.4 & 94.8 & 95.7 & 99.0 & 99.9 & 103.3 & 104.0 & 106.7 & 107.3 \\
\hline
\end{tabular}

F: Female; M; Male, P: Patients, WHO: World Health Organization

WHO data available at: https://www.who.int/tools/child-growth-standards/standards 
time in different private and public healthcare centers. Also, the order of child birth, the child sex, distance to healthcare centers, the mother age and pregnancy care, health system coverage and follow-up measures are highly effective on the children $\mathrm{CH}$ screening [11]. This emphasizes more than ever the importance of information exchange and cooperation between the various public and private sectors in the provision of services. In addition, different countries use different cut points to screening for hypothyroidism. In Greece, for example, infants with TSH more than 20 are considered as suspicious cases [27]. In Egypt, however, the amount more than 15 are considered for further evaluation [28]. In the Iranian screening program, which started from 2005, TSH value greater than 5 is considered as cases needing more follow-up measures [21]. Another important point about preventing $\mathrm{CH}$ is intervention on the changeable factors. A study in Iran showed that consanguineous marriages, low birth weight, type of delivery, infant hospitalization (for various reasons) have significant effects on the $\mathrm{CH}$ development. These indicate that screening program alone in the public healthcare system is not enough to preventing $\mathrm{CH}$ development, but also it is necessary to integrate all private and first, second, and third levels of healthcare system in order to provide a comprehensive view of the issue. Primary Health Care (PHC) system of Iran has indicated its effectiveness, efficiency and hence productivity in different conditions and crises [29]. Improving social capital and KAP of parents, and supporting low socioeconomic groups are effective in the successful prevention measures [30]. Fortunately, prevention and treatment of $\mathrm{CH}$ similar to other PHC services does not need expensive and complicated equipment and is presentable affordable within the current facilities [31, 32].

\section{Conclusion}

This study showed that the program of neonatal screening for early detection and treatment of $\mathrm{CH}$ cases has achieved great successes. However, as the study indicated, three and a half years old $\mathrm{CH}$ children in comparison with their healthy counterparts have some limited problems in developmental categories. In order to reduce the complications of congenital hypothyroidism in the affected children, it is necessary to implement the screening, treatment and follow up measures uniformly and coherently across the country on the basis of WHO and national guidelines. Identifying the weaknesses and threats of the program and providing information on its shortfalls can inform policymaking and channel resource allocations.

\section{Acknowledgements}

The researchers would like to thanks research deputy of Arak University of Medical Sciences, Arak, Iran, for supporting this study.

\section{Authors' contributions}

JN, MC, KJ, and SA designed the study and interpreted the data. JN and SA wrote the main manuscript text. MC, AM, KJ, and PM conducted the survey and analyzed the data. All authors read and approved the final manuscript.

Funding

This study was funded by Arak University of Medical Sciences.

\section{Availability of data and materials}

The datasets analyzed during the current study are available from the corresponding author on reasonable request.

\section{Declarations}

\section{Ethics approval and consent to participate}

Informed and written consent was obtained from the parents of the children in the case and control groups before starting the work. This study has been approved by the Ethics in research committee of Arak University of Medical Sciences (Ethics Code IR.ARAKMU. REC.1398. 208).

\section{Consent for publication}

Not applicable.

\section{Competing interests}

The authors declare that they have no competing interests.

\section{Author details}

'Department of Pediatrics, Medical School, Arak University of Medical Sciences, Arak, Iran. ${ }^{2}$ Health Deputy, Arak University of Medical Sciences, Arak, Iran. ${ }^{3}$ Department of Forensic Medicine, School of Medicine, Arak University of Medical Sciences, Arak, Iran. ${ }^{4}$ Department of Health, Khomein University of Medical Sciences, Khomein, Iran. ${ }^{5}$ Department of Health Services Management, Health School, Arak University of Medical Sciences, Arak, Iran.

Received: 30 January 2021 Accepted: 14 September 2021

Published online: 23 September 2021

\section{References}

1. Menchise A. WF B. Philadelphia: Wilson disease. Nelson textbook of pediatrics. Twentieth Edition. Elsevier Inc.; 2016. p. 1939-40.

2. Salim FA, Varma SK. Varma, congenital hypothyroidism and the importance of universal newborn screening. Indian J Pediatr. 2014;81(1):53-7.

3. Unüvar T, Demir K, Abacı A, Büyükgebiz A, Böber E. The role of initial clinical and laboratory findings in infants with hyperthyrotropinemia to predict transient or permanent hypothyroidism. J Clin Res Pediatr Endocrinol. 2013;5(3):170-3.

4. Feizi A, Hashemipour M, Hovsepian S, Amirkhani Z, Kelishadi R, Yazdi M, et al. Growth and specialized growth charts of children with congenital hypothyroidism detected by neonatal screening in isfahan, iran. Int Sch Res Notices. 2013: 463939.

5. Deladoey J, Ruel J, Giquere Y, Van Vliet G. Is the incidence of congenital hypothyroidism really increasing? A 20-year retrospective populationbased study in Quebec. J Clin Endocrinol Metabol. 2011;96(8):2422-9.

6. Fan X, Chen S, Qian J, Sooranna S, Luo J, Li C, et al. Incidence and interrelated factors in patients with congenital hypothyroidism as detected by newborn screening in Guangxi, China. Global pediatric health. 2015;2:2333794X14567193.

7. Yarahmadi S, Ajhang N, Sayari AA, Kousha A. Progress report on national program of congenital hypothiroidism, 2011-2015: Mojasame publication. Ordered by Bureau of Non-communicable Diseases, Endocrine and Metabolic Department, Health Deputy of Ministry of Health and Medical Education of Iran. 2016. 
8. Khabiri SR, Pordanjani SR. A comparison of healthy children and children of patients with congenital hypothyroidism treated under treatment with Some evolutionary indicators. J Birjand Univ Med Sci. 2017;24(3):199-206.

9. Sun Q, Chen Y-L, Yu Z-B, Han S-P, Dong X-Y, Qiu Y-F, et al. Long-term consequences of the early treatment of children with congenital hypothyroidism detected by neonatal screening in Nanjing, China: a 12-year follow-up study. J Trop Pediatr. 2012;58(1):79-80.

10. Van der Sluijs VL, Kempers M, Last B, Vulsma T, Grootenhuis M. Quality of life, developmental milestones, and self-esteem of young adults with congenital hypothyroidism diagnosed by neonatal screening. J Clin Endocrinol Metab. 2008;93(7):2654-61.

11. Mahmoudi F, Mohmmad K, Eftekhar H, Mansouri K, Garibnavaz H, Ershadi $A$, et al. Causes of inadequate coverage of screening programs for congenital diseases in infants born in north health center area. Tehran Hakim Res J. 2013;15(4):281-7.

12. Najafian B, Shahverdi E, Afsharpaiman S, Shohrati M, Karimi S, Konjedi MA. Neonatal screening for congenital hypothyroidism in an university hospital in Tehran, Iran. J Compr Pediatr. 2016;7(2):e34500

13. Mehran L, Yarahmadi S, Khalili D, Hedayati M, Amouzegar A, Mousapour $\mathrm{P}$, et al. Audit of the congenital hypothyroidism screening program in 15 Provinces of Iran. Arch Iran Med. 2019;22(6):310-7.

14. Yar-Ahmadi Shahin. National Neonatal Hypothyroidism Screening Program for Iran- Physician version. Iran Ministry of Health and Medical Education. 2012. Available at: https://baharestan.iums.ac.ir/files/bahar estan/files/TIRO.pdf. Last accessed: 6/29/2021.

15. Squires J, Bricker D, Twombly E. Ages \& stages questionnaires ${ }^{\circledR}$ : socialemotional, second edition (ASQ ${ }^{\circledR}:$ SE-2): A parent-completed child monitoring system for social-emotional behaviors. Baltimore: Paul H. Brookes Publishing Co., Inc.; 2005.

16. Squires J, Bricker D. Ages \& stages questionnaires ${ }^{\circledR}$, third edition (ASQ ${ }^{\circledR}-3$ ): A parent-completed child monitoring system. Baltimore: Paul H. Brookes Publishing Co., Inc:; 2009.

17. Bayley, N. Bayley scales of Infant development 3rd edition, technical manual. PsychCorp, Harcourt Assessment, Inc.; San Antonio, TX. 2006.

18. Wechsler D. WPPSI-III: technical and interpretative manual. San Antonio, TX: The Psychological Corporation. 2002;19(1-2):205-20.

19. Raeissi N, Moafi A, Alikhasi N. Comparison of CNS relapse, survival and intelligent quotient in non-high risk all children treated with intrathecal methotrexate or triple intrathecal therapy. Int J Pediatr. 2019;7(8):9955-65.

20. National project to achieve cutting points for the screening tools of ASQSE and ASQ3 for child development. Iran Ministry of Health and Medical Education. 2019. Available at: https://behdasht.gov.ir/. Last accessed: 11/23/2020. 2019.

21. Veisani Y, Sayehmiri K, Rezaeian S, Delpisheh A. Congenital hypothyroidism screening program in iran; a systematic review and metaanalysis. Iran J Pediatr. 2014;24(6):665.

22. AliMohammadzadeh K, Yarahmadi S, Tabibi S, Nasiripour A. Rate of saving health in program of screening for congenital hypothyroidism (CH) in Iran. Sci Res Essays. 2011;6(8):1873-6.

23. Rahmani K, Yarahmadi S, Etemad K, Mehrabi Y, Aghang N, Koosha A et al. Intelligence quotient at the age of six years of Iranian children with congenital hypothyroidism. Indian pediatr. 2018:55(2):121-4.

24. Rezaeian S, Poorolajal J, Moghimbegi A, Esmailnasab N. Risk factors of congenital hypothyroidism using prop ensity score: a matched casecontrol study. J Res Health Sci. 2013;13(2):151-6.

25. Khammarnia M, Siakhulak FR, Ansari H, Peyvand M. Risk factors associated with congenital hypothyroidism: a case-control study in southeast Iran. Electron physician. 2018;10(2):6286.

26. Ford G, LaFranchi SH. Screening for congenital hypothyroidism: a worldwide view of strategies. Best Pract Res Clin Endocrinol Metab. 2014:28(2):175-87.

27. Skordis N, Toumba M, Savva SC, Erakleous E, Topouzi M, Vogazianos M, et al. High prevalence of congenital hypothyroidism in the Greek Cypriot population: results of the neonatal screening program 1990-2000. J Pediatr Endocrinol Metab. 2005;18(5):453-61.

28. Bekhit OE, Yousef RM.Yousef, Permanent and transient congenital hypothyroidism in Fayoum, Egypt: a descriptive retrospective study. PloS one. 2013.8(6):e68048.

29. Nazari J, Amini S, Amiresmaili M. Lessons learned to control COVID-19 to prevent a crisis: the case of Iran. Open Public Health J.2020.13(1).
30. Dehnavieh R, Amini S. Social capital and its effects on health: implications for policy makers. Iran J Public Health. 2015;44(11):1566-7.

31. Barouni M, Amiresmaieli MR, Shahravan A, Amini S. The efficiency assessment of dental units using data envelopment analysis approach: The case of Iran. Iran J Public Health. 2017:46(4):552.

32. Amiresmaili M, Amini S, Shahravan A, Goudarzi R, Anari SHS, Anbari Z, et al. Relation between socioeconomic indicators and children dental caries in Iran: a systematic review and meta-analysis. Int J Prev Med. 2018:9:71.

\section{Publisher's Note}

Springer Nature remains neutral with regard to jurisdictional claims in published maps and institutional affiliations.
Ready to submit your research? Choose BMC and benefit from:

- fast, convenient online submission

- thorough peer review by experienced researchers in your field

- rapid publication on acceptance

- support for research data, including large and complex data types

- gold Open Access which fosters wider collaboration and increased citations

- maximum visibility for your research: over 100M website views per year

At BMC, research is always in progress.

Learn more biomedcentral.com/submissions 